Advances in Technology has helped in saving many innocent lives. Health sciences have improved leaps and bounds. Medical Professionals have embarked on medical technological tools to carry out extensive research on human health problems. The fruits of this research has resulted into the development of new drugs, and treatments which have helped in curing most challenging human diseases and it has also prolonged the human lifespan. Rapidly changing technology and availability of new innovative technology in diagnostic and therapeutic fields together with changing practice pattern of clinicians has revolutionized the way health care is being delivered today globally.

New Innovations which can change the world. I have chosen few important innovations which can help health care delivery more scientifically.

Smart phone Ultrasound: Experts at the Washington University in St. Losuis managed to integrate a USB based ultrasound probe with a Smart phone. The main goal was to create an simple hand sized "Ultrasound device" that can enable doctors in remote areas to image a patients kidney, liver, bladder, eyes, veins and arteries so that they can easily detect any infections. This type of device can be of a good use in many developing countries and it can help in saving lives. Doctors without boundaries can use this mobile ultra sound to help out many patients in remote areas.

Technological advancements in communication: Communication is a major factor in both human lives and business. With years this technology has evolved and we have witnessed new mobile phones which made communication easier. With its technology, you can even do a live video call and see the people you're communicating with.

Human Head Transplants: Sergio Canavero, an Italian neurosurgeon, intends to attempt the first human head transplant by 2017, though no successful animal transplants with long-term survival have yet been made. Because of the difficulty of connecting the spinal cord, Canavero has suggested improvements in the process using a special blade and polyethylene glycol, a polymer used in medicine as well as in everything from skin cream to the conservation of the Mary Rose, can help start growth in spinal cord nerves. Being able to surgically remove the head in an orderly fashion should allow surgeons to then reattach all the nerves and blood vessels to the new body, once that pesky donor head is removed. A special bio-compatible glue will hold the spinal cord together so it can fuse with the donor body. The patient will then be put in a drug-induced coma for four weeks while the connection between the head and body heals. It's the reattachment process that's the most unlikely part of all this. There's never been a successful procedure that reattached a fully severed primate spinal cord.

Heart in a Box: Warm Blood Perfusion System: Cardiac transplantation, also called heart transplantation, has evolved into the treatment of choice for many people with severe heart failure who have severe symptoms despite maximum medical therapy. Survival among cardiac transplant recipients has improved as a result of improvements in treatments that suppress the immune system and prevent infection.

Advanced Immunotherapies to Treat Cancer: Scientists at Juno Therapeutics reported at the American Society of Hematology (ASH) meeting that, in an ongoing Phase 1 trial, its chimeric antigen receptor (CAR) T-cell therapy, JCAR015, put 24 of 27 adults with refractive acute lymphoblastic leukemia (ALL) into remission, with six patients remaining disease free for more than a year (ASH 2014, Abstract 382, 2014).

Young Blood Antiaging - Fountain of Youth? Is the fountain of youth becoming a reality? A new treatment option maybe in our future in which blood of younger people under 25 could be used to reverse the effects of aging. 


\section{From the Editors Desk}

Consumerism in Healthcare: Consumerism has been making inroads into the healthcare industry for at least a decade, with patients increasingly acting like consumers who have a choice in their healthcare options, trying to make the best decisions for quality and cost just as they do with any other commodity. The trend has been accelerated by the Patient Protection and Affordable Care Act, which left many consumers with large deductibles that put more pressure on them to find the most cost-effective care for the dollars coming out of their own pockets.

Genomics Editing/Splicing: Genome editing is a way of making specific changes to the DNA of a cell or organism. An enzyme cuts the DNA at a specific sequence, and when this is repaired by the cell a change or 'edit' is made to the sequence. Intellia is a leading genome editing company, focused on the development of proprietary, potentially curative therapeutics using a recently developed biological tool known as the CRISPR/Cas9 system. Intellia believes the CRISPR/Cas9 technology has the potential to transform medicine by permanently editing disease-associated genes in the human body with a single treatment course

Bioabsorbable Stents: Every year, 600,000 people have metal coronary stents put into their chests to treat coronary artery blockage. Most of the time, that stent stays there forever, long after its mission is complete. The stents may inhibit natural blood flow and cause other complications, like blood clots. What if they could just disappear? That is a long-sought goal researchers have finally met. This past July, the first bioabsorbable stent was approved in the United States. Made of a naturally dissolving polymer, the stent widens the clogged artery for two years before it is absorbed into the body in a manner similar to dissolvable sutures.

However technology has also caused us concerns. Its poor application has resulted into the pollution of the environment which has serious threat to our lives and society. This calls for proper use of technology. The biggest challenge facing people is to determine the type of future we need to have and then create relevant technologies which will simplify the way we do things.

(Ref: 17 Amazing Healthcare Technology Advances of 2017- referral md.)

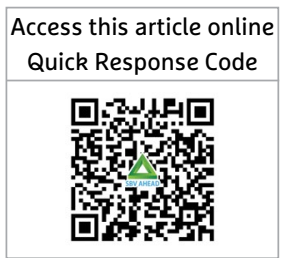

Dr.S.Joseph Philipraj, MBBS, DipNB, MS, MCh,DipNB,MNAMS,

MBA- Hosp management

Professor- Urology

Sri Balaji Vidyapeeth - Mahatma Gandhi Medical College and Research Institute Campus Pillaiyarkuppam, Puducherry - 607403, India 